\title{
Методологический подход к разработке и реализации стратегии институциональных преобразований промышленного комплекса
}

\author{
Алексей Боев \\ Аналитический центр правительства Воронежской области, Воронеж, Россия
}

\author{
Информация о статье \\ Поступила в редакцию: \\ 19.11.2019 \\ Принята \\ к опубликованию: \\ 19.12.2019 \\ УДК 338; 658 \\ JEL L20
}

\section{Ключевые слова:}

методология, методологический подход, стратегия институциональных преобразований, промышленный комплекс, цифровая экономика

\section{Keywords:}

methodology, methodological approach, strategy of institutional transformation, industrial complex, digital economy

\begin{abstract}
Аннотация
Статья посвящена формированию методологии разработки и реализации стратегии институциональных преобразований промышленных комплексов в условиях ияифровой экономики. Предложены авторские определение и структурносодержательная схема методологии. Сформирована методологическая матрица, систематизирующая категориальный апnарат, принцииь, подходы, методики, методы и модели построения стратегии по уровням научного знания. Разработан алгоритмизированный методологический подход к созданию и реализации стратегии институцинональной трансформации промышленного комплекса в изифровой среde.
\end{abstract}

Methodological Approach to the Development and Implementation of the Strategy for the Industrial Complex Institutional Transformation

Alexey Boev

Abstract

The paper is devoted to creating the methodology and to the topical issues of developing and implementing the strategy for the industrial complexes institutional transformations under the conditions of the digital economy.

The paper investigates general scientific and economic understanding of the methodology notion, shows its specific characteristics. The definition of the methodology for developing and implementing the strategy for the industrial complex transformations was proposed. It is an integrated set of principles, approaches and tools, united by a common logic of construction and the relevant categorical apparatus, that allows to solve theoretical and conceptual, organizational, economic, managerial and other issues of institutional strategy, digital innovations and enterprise transformation.

The methodological matrix, which systematizes categorical apparatus, principles, approaches, methods and models of the strategy development according to the levels of scientific knowledge was generated. 
The structural scheme of the methodology and algorithm-based methodological approach to the development and implementation of the strategy for the industrial complex institutional transformation in the digital environment were developed. The content of each stage of the methodological approach was substantiated.

The means of the investigation included the general-scientific and special methods: analysis, synthesis, structuring and description, systems and process approaches.

The results of the investigation can be used as a theoretical and methodological basis for the formation and implementation of the strategy for the industrial complex transformation in the digital economy.

\section{Введение}

Разработка и реализация стратегии институциональных преобразований промышленных комплексов в условиях цифровой экономики является сложным, многоаспектным и межфункциональным процессом, для комплексного понимания и управления которым недостаточно моноотраслевого инструментария и требуется интегрированное научно-практическое знание, оформленное в виде методологии.

Значительный вклад в развитие общенаучных и экономических аспектов методологии стратегического управления и развития экономических систем внесли И. Ансофф [1], Г. Минцберг [2], К. Торли, Х. Уирдениус, Дж. Коттер [3], Л. Шлезингер, П. Сенге [4], Д. Кэмпбел [5], Г.П. Щедровицкий, Л.В. Кантарович, П.Я. Гальперин, Т. Кун, В.В. Новожилов, Ю.П. Анисимов, А.И. Пригожин и др.

Особое значение методологии отмечает Г.П. Щедровицкий. По его мнению, наши представления об объекте, да и сам объект как особая организованность, задаются и определяются не только и даже не столько материалом природы и мира, сколько средствами и методами нашего мышления и нашей деятельности [6].

В настоящее время в экономической науке нет единого и общепризнанного понятия методологии. Наиболее широкий спектр взглядов на ее определение можно проследить в агрегированном энциклопедическом знании и обзорных работах различных исследователей. В них методология преимущественно определяется как учение о научном методе познания, принципы и способы организации теоретической и практической деятельности, совокупность приемов и технологий исследования, методы, приёмы, используемые при познании чего-либо и объединённые общей целью, исходные положения о структуре, функциях и методах научных исследований [7-9].

Мы выделили важнейшие черты методологии, отличающие ее от теоретического и иного знания.

1. Интегрированность философско-мировоззренческого, общенаучного, отраслевого экономического и специализированного (технологического) знания. Данная особенность коррелирует с идеей А.И. Пригожина, согласно которой «каждый угол зрения на организацию нуждается в своем самостоятельном развитии, но в рамках целостной науки; выход исследований на постдисциплинарный уровень задает им новую меру комплексности подхода за пределами специализации» [10].

2. Объединение инструментария познания и преобразования предмета исследования. Иными словами, наряду с теорией научно-исследовательской (познавательной) деятельности методология также включает собственную теорию преобразовательной (практической) деятельности [11]. 


\section{Методология исследования}

На основании вышеизложенного автор рассматривает методологию разработки и реализации стратегии институциональных преобразований промышленных комплексов как объединенную общей логикой построения и профильным категориальным аппаратом целостную совокупность принципов, подходов и инструментов (методик, методов, моделей и т.д.) различного уровня научнопрактического знания, позволяющую решать теоретико-концептуальные, организационные, экономические, управленческие и иные базовые вопросы исследования, формирования и реализации стратегии институциональной, цифровой и инновационной трансформации предприятия.

Автор предлагает выделить четыре уровня методологии разработки и реализации стратегии институциональных преобразований промышленных комплексов (рис. 1):

1) философско-мировоззренческий - наиболее общие результаты научного знания, а также элементы фундаментальных основ миропознания и миропонимания, которые формируют представление о природе, смысловом содержании и логике деятельности человека по преобразованию материи и взаимодействии с другими субъектами экосистемы;

2) общенаучный - междисциплинарное и межотраслевое научное знание, представляющее собой систему универсальных теоретических, методических, прикладных и иных результатов, которые могут использоваться для решения практически неограниченного круга научных и практических задач, стоящих перед обществом потребления;

3) отраслевой экономический - экономическое теоретическое и научнопрактическое знание, основным предметом изучения которого выступают общественные отношения, складывающие вокруг процесса производства, реализации и распределения материальных и нематериальных благ, товаров, работ и услуг в целях удовлетворения потребностей населения;

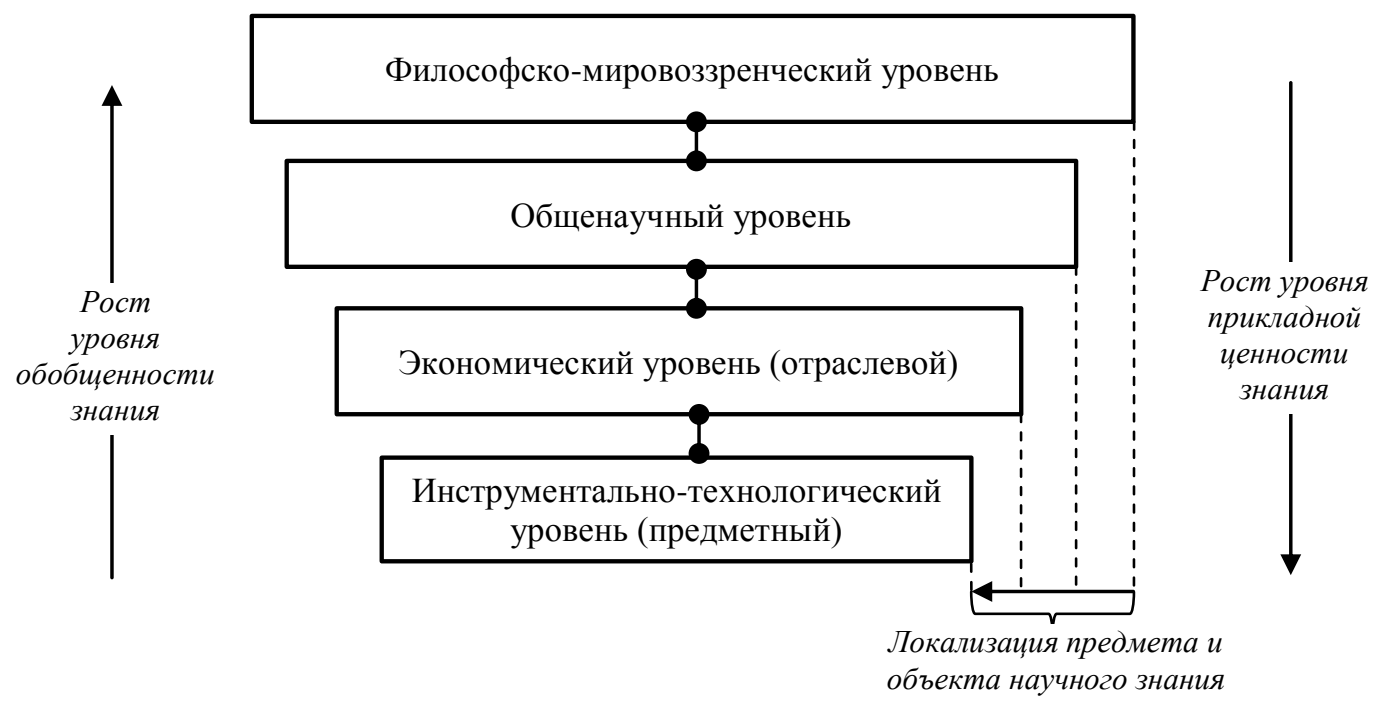

Puc. 1. Уровни методологии разработки и реализации стратегии институциональных преобразований промышленных комплексов в условиях цифровой экономики

Источник: составлено автором 
4) инструментально-технологический - специализированное экономическое знание преимущественно прикладного характера, оформленное в виде конкретных подходов, принципов, методик, методов, моделей и иного инструментария, предназначенное для разработки и реализации стратегии институциональных преобразований промышленных комплексов в условиях цифровой экономики.

По мнению автора, инструментально-технологический уровень формирует основную научно-практическую ценность методологии, так как он детализирует академическое знание до уровня конкретных категорий, методик, подходов и технологий, которые позволяют обеспечить достижение поставленных целей и задач исследования, сформировать инструментарий для решения основных стратегических вопросов трансформации предприятий в цифровой среде, а также спрогнозировать сценарии получения необходимых результатов и оценить эффективность их реализации для определенных индустриальных компаний.

Определение иерархии уровней методологии неразрывно связано с задачей ее содержательного наполнения. Автором предложены четыре базовых структурно-содержательных элемента методологии разработки и реализации стратегии институциональных преобразований промышленных комплексов:

1) категориальный аппарат - система взаимосвязанных категорий, комплексно раскрывающих содержание различных аспектов стратегии институциональных преобразований промышленных комплексов в условиях цифровой экономики и позволяющих ее идентифицировать в пространстве теоретикометодологического и научно-практического знания;

2) подходы - общие алгоритмы изучения, разработки, преобразования и реализации стратегии институциональных изменений индустриального предприятия, основанные на интеграции в единую логику взглядов и действий концептуальных, стратегических, организационных, экономических, управленческих и иных этапов, шагов и мероприятий;

3) принципы - система исходных ориентиров, приоритетов и положений, на которых строится исследование или преобразование процесса трансформации промышленного комплекса в рамках цифровой экономики;

4) инструментарий - теоретико-методические и научно-практические разработки (конкретные методы, методики, модели и т.д.), формирующие ядро методологии и выступающие непосредственным «орудием» оценки, анализа, построения и преобразования стратегии институциональных изменений промышленного комплекса и сопряженных с ней элементов, процессов, систем и отношений. В отличие от других элементов методологии инструментарий состоит из набора средств, которые позволяют исследовать и развивать объект наиболее детально и комплексно.

Предложенный состав элементов методологии является оптимальным и создает содержательное единство теоретических и методических аспектов разработки и реализации стратегии преобразований промышленных комплексов в условиях цифровой экономики. Необходимо отметить, что отдельные исследователи не включают в структурно-содержательный состав методологии категориальный аппарат, принципа или подходы, ограничиваясь преимущественно инструментарием. Исключение из состава методологии указанных элементов является некорректным и создает проблему формирования неполной, «обедненной» и выхолощенной методологии, которая будет иметь достаточно огра- 
ниченный уровень применения.

На основе объединения уровней и элементов методологии сформирована методологическая матрица разработки и реализации стратегии институциональных преобразований промышленных комплексов в условиях цифровой экономики, которая представлена в табл.

Методология разработки и реализации стратегии институциональных преобразований промышленных комплексов в условиях цифровой экономики представлена на рис. 2. Содержание методологии сгруппировано в три структурных блока:

1) теоретико-методологический базис методологии, объединяющий категориальный аппарат, общие и частные принципы институциональных изменений, концепцию и процесс трансформации промышленных комплексов, а также систему стратегического управления преобразованиями;

2) инструментальное ядро методологии, которое включает совокупность методик институциональных преобразований и перечень взаимосвязанных методических положений, подходов, моделей и методов стратегии изменений промышленных комплексов в условиях цифровой экономики;

3) тактический организационно-управленческий инструментарий, основными элементами которого выступают механизм реализации стратегии преобразований промышленного комплекса и процедура внедрения цифровой платформы.

\section{Результаты}

Одним из базовых элементов методологии является предложенный подход к разработке и реализации стратегии институциональной трансформации промышленного комплекса в условиях цифровой экономики. Дадим характеристику основным этапам (рис. 3).

1. Комплексный аудит деятельности промышленного комплекса. На этапе аудита проводится анализ рыночного положения производственного предприятия, определяются его конкурентные возможности и угрозы, преимущества и недостатки, позитивные и негативные факторы влияния, анализируется уровень научно-технологического, инновационного, индустриального, цифрового и иного развития, осуществляется инвентаризация накопленных проблем и противоречий на уровне внутренней и внешней среды.

Ключевой целью аудита выступает формирование объективного и системного понимания хозяйственно-экономического состояния и потенциала промышленного комплекса, а также создание информационно-аналитической базы для разработки и реализации стратегии изменений.

Методическим инструментарием для проведения аудита могут выступить методы и технологии финансового-экономического анализа, многомерной оценки потенциала, анализ инерционного сценария развития промышленного комплекса, SWOT-, LOTS-, GAP-, PIMS-, PEST-анализ, построение моделей жизненного цикла, BCG-матрицы и иные средства. 
А. Г. Боев // Известия ДВФУ. Экономика и управление. 4. 2019. 69-81

Таблицุа

Методологическая матрица разработки и реализации стратегии

институциональных преобразований

промышленных комплексов в условиях цифровой экономики

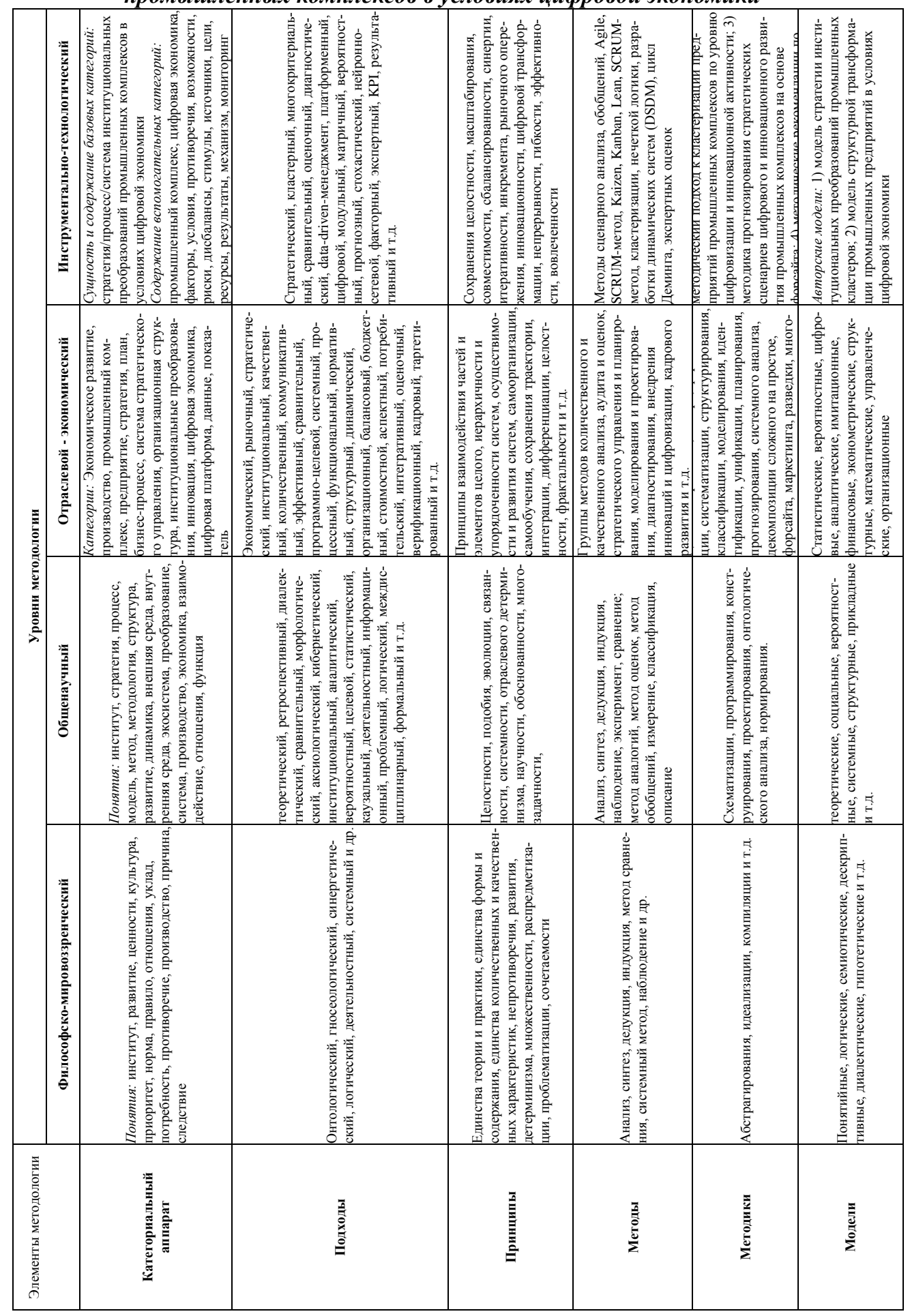


А. Г. Боев // Известия ДВФУ. Экономика и управление. 4. 2019. 69-81

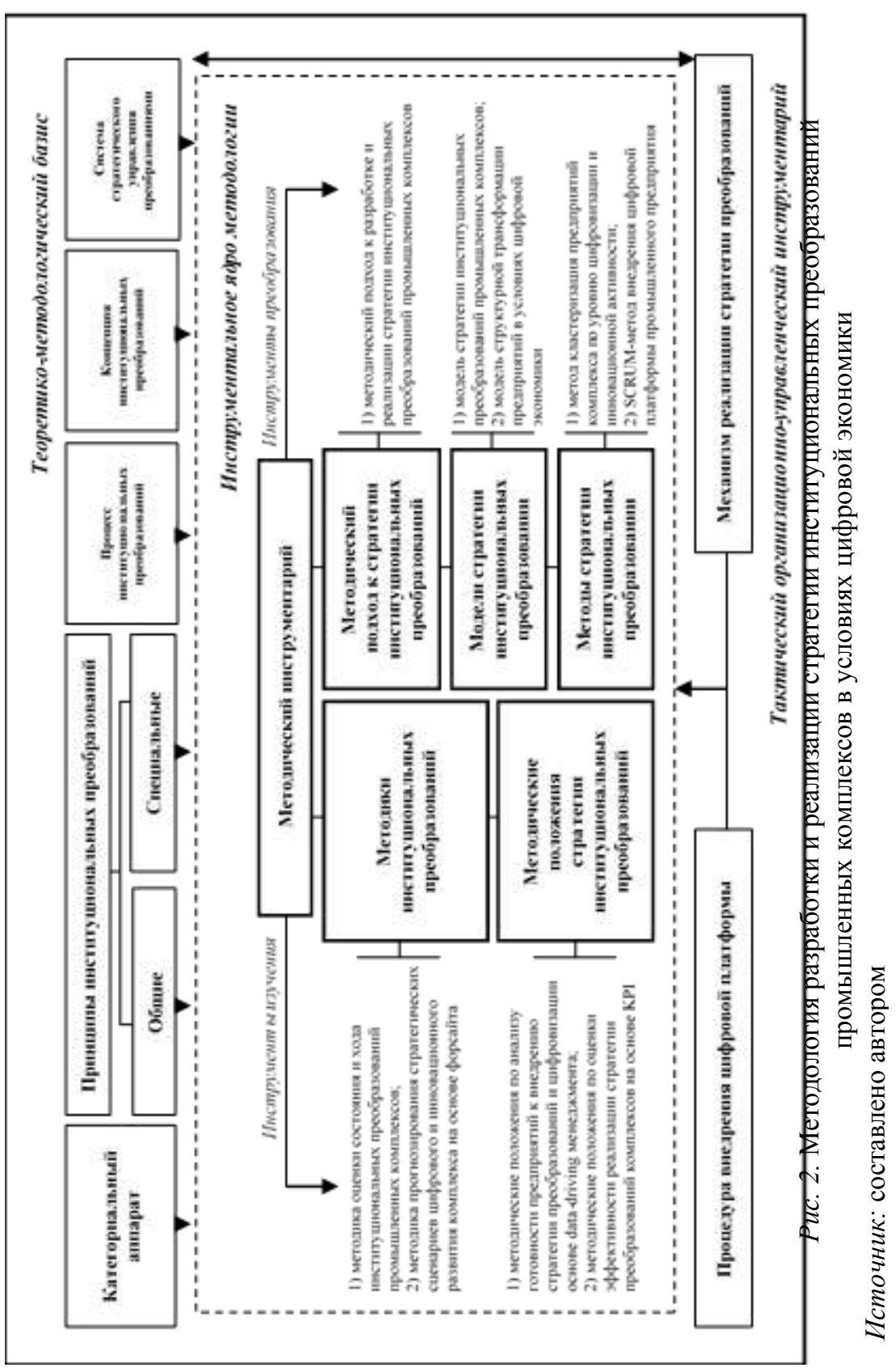


А. Г. Боев // Известия ДВФУ. Экономика и управление. 4. 2019. 69-81
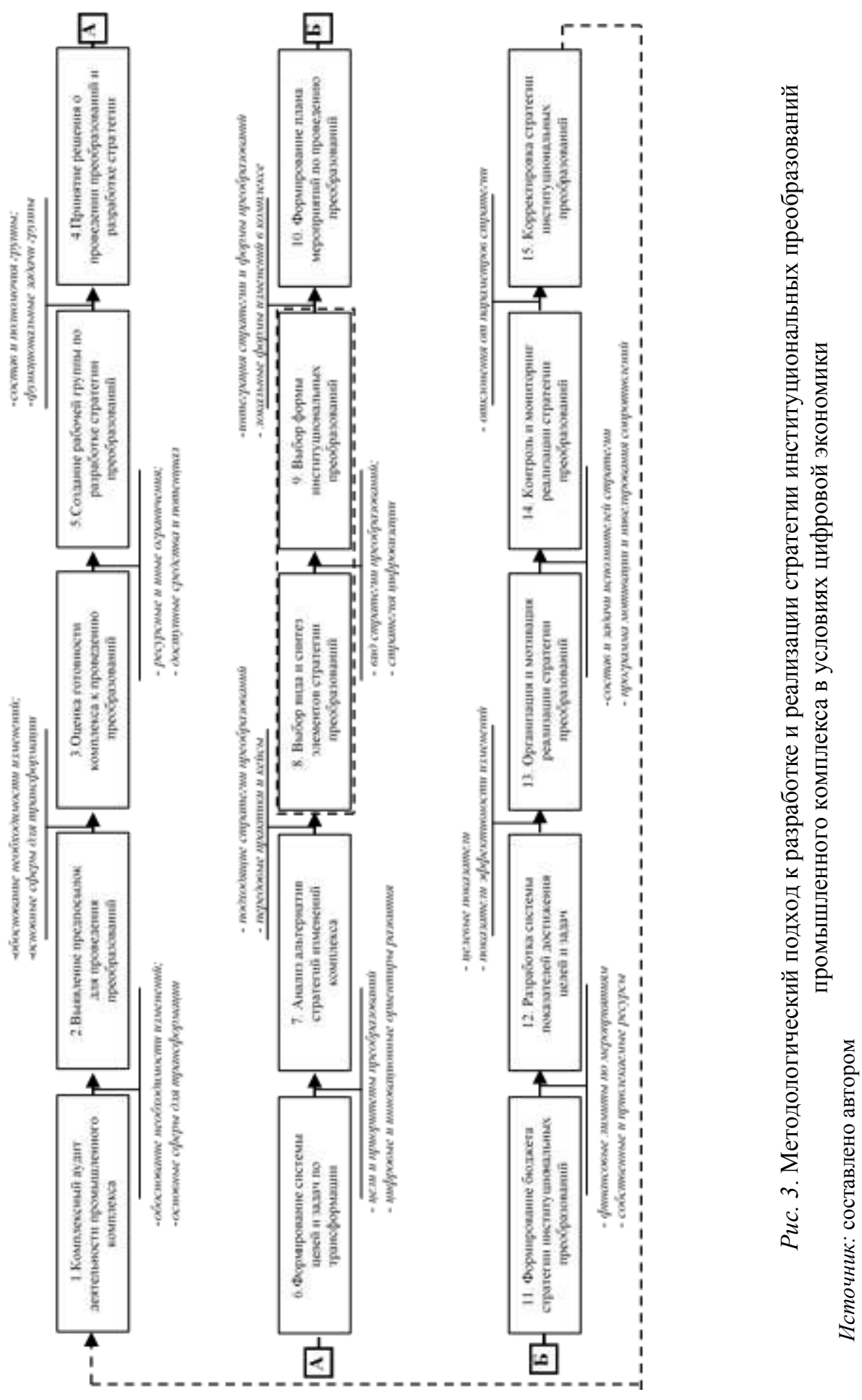
2. Выявление предпосылок для проведения преобразований предполагает оценку глубины, комплексности и характера выявленных на предприятии проблем и открывающихся возможностей. В случае, если указанные проблемы могут быть решены, а возможности реализованы в рамках текущей модели функционирования и развития промышленного комплекса, то институциональные преобразования не требуются и предпосылки для них отсутствуют. В то же время, если существующие проблемы и противоречия не могут быть нивелированы за счет штатных мероприятий и имеют потенциал масштабирования, то они формируют предпосылки для трансформации или сами выступают в их качестве.

Выявление предпосылок является важнейшим этапом для обоснования целесообразности институциональных преобразований на предприятии и формирования круга сфер и направлений, требующих изменений в первоочередном порядке.

3. Оченка готовности комплекса к проведению преобразований - предусматривает исследование потенциальной кадровой, организационной, управленческой, экономической, технологической и иной готовности предприятия и его контрагентов к реинжинирингу ключевых бизнес-процессов и изменению модели функционирования (взаимодействия).

В рамках данного этапа определяются доступные средства и активы для проведения преобразований, а также выявляются ресурсные, квалификационные, временные и другие ограничения.

4. Принятие решения о проведении преобразований является актом стратегического управленческого действия и «точкой входа» в разработку стратегии и организацию процесса трансформации промышленного комплекса. Указанное решение может быть оформлено документально и доведено до персонала предприятия.

5. Создание рабочей группы по разработке стратегии преобразований предполагает формирование кроссфункциональной команды, которая будет выполнять координирующую роль в процессе формирования и реализации стратегии изменений промышленного комплекса.

В состав команды включаются представители топ-менеджмента и руководители структурных подразделений предприятия, а также (при необходимости) независимые эксперты и консультанты, IT-специалисты и специалисты по автоматизации и цифровизации бизнеса, работники вузов, научноисследовательских организаций и т.д.

На этапе создания рабочей группы определяется ее управленческий статус, круг полномочий и решаемых задач и иные важные параметры деятельности.

6. Формирование системы целей и задач по трансформации включает определение ключевых инновационных, цифровых и иных приоритетов развития промышленного комплекса, а так же построение взаимосвязанного и непротиворечивого перечня целей и задач, достижение которых позволит принципиально повысить конкурентоспособность предприятия, решить накопленные проблемы и противоречия, реализовать открывающие возможности в условиях цифровой экономики.

В качестве инструментария генерации и формирования системы целей могут выступить различные методы экспертной работы, сравнительный анализ, бенчмаркинг и другие. 
Для формулирования целей и задач целесообразно в том числе использовать SMART-критерии, которые устанавливают требования конкретности, измеримости, достижимости, релевантности и определенности во времени.

7. Анализ альтернатив стратегий изменений комплекса предполагает построение банка стратегических альтернатив комплексной трансформации и цифрового развития промышленного комплекса с последующей их оценкой на предмет потенциальной эффективности, ресурсоемкости и возможности реализации.

8. Выбор вида и синтез элементов стратегии преобразований осуществляется по итогам рейтингования и ранжирования доступных предприятию стратегических альтернатив и предполагает определение базового вида стратегии изменений на основе компиляции наиболее эффективных и конкурентоспособных элементов из рассматриваемых направлений.

Для осуществления выбора вида (типа) стратегии преобразования менеджментом предприятия могут использоваться как традиционные классификации стратегий изменений К. Торли, Х. Уирдениуса (директивная, основанная на переговорах, нормативная, аналитическая, ориентированная на действия), Л.Д. Гительмана, Б.Е. Ратниковой, Г. Минцберга [2], так и их комбинации, различные авторские интерпретации и вариации [12-14].

Важнейшим элементом, сопутствующим выбору вида стратегии преобразований, является определение временного периода (срока) ее разработки и реализации.

9. Выбор формы институциональных преобразований. Этап предусматривает выбор менеджмента предприятия между инновационной, оптимизирующей, катализирующей, балансирующей, структурирующей, интегрирующей и масштабирующей формами проведения изменений, а также определение локальных форм трансформации функциональных сфер или структурных подразделений. При этом необходимо отметить, что на предприятии должен быть обеспечен принцип единства и непротиворечия вида стратегии и формы институциональных преобразований.

10. Формирование плана мероприятий по проведению преобразований. План является системой документов, которая содержит конкретизированные меры по достижению целей и ожидаемых результатов стратегии, взаимоувязанные по срокам, технологиям, бюджетам и ответственным исполнителям. Рекомендуемая система планов трансформации промышленного комплекса представлена на рис. 4.

11. Формирование бюджета стратегии институциональных преобразований предполагает определение лимитов ресурсов, которые могут быть направлены на выполнение плана, программ, проектов и мероприятий по реализации стратегии и достижению установленных значений целевых показателей по трансформации промышленного комплекса.

Необходимо отметить, что разработка и принятие классического жестко формализованного бюджета стратегии изменений могут быть затруднены в случае, если предприятие предполагает реализацию отдельных проектов по цифровизации и инновационному развитию на основе применения гибких методов и методологий проектного управления (например, AGILE, SCRUM и другие), сопряженных с использованием адаптивного или ситуационного планирования (в том числе в финансовой сфере). 


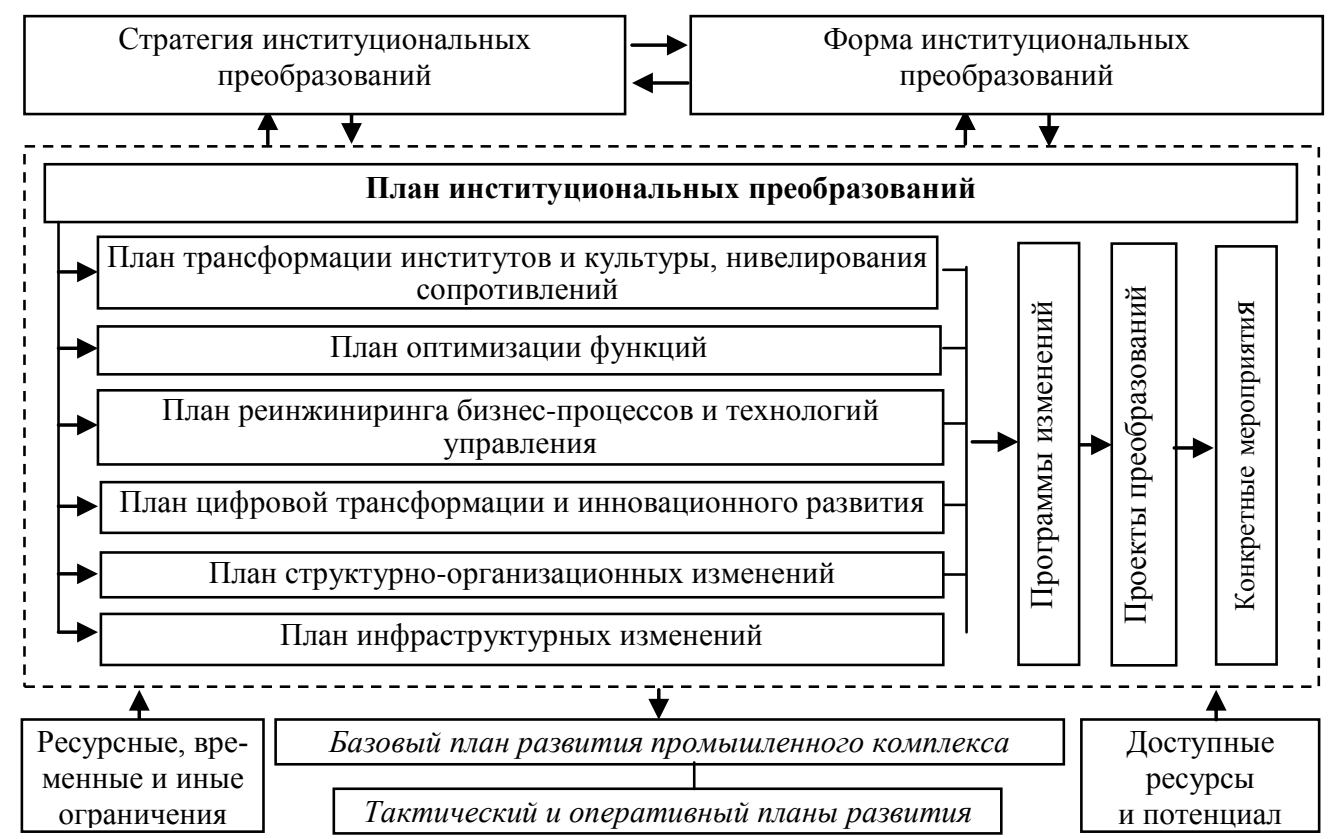

Puc. 4. Рекомендуемая система планов трансформации промышленного комплекса в условиях цифровой экономики

Источник: составлено автором

12. Разработка системы показателей достижения иелей и задач состоит в формировании совокупности взаимосвязанных и сбалансированных количественных и качественных параметров, индикаторов и показателей, позволяющих отслеживать динамику достижения целевого состояния промышленного комплекса, а также корректировать и актуализировать стратегию преобразований на основе полученных данных.

В систему наблюдаемых показателей целесообразно включить показатели, характеризующие рыночное, финансово-экономическое, производственнотехнологическое, цифровое, инновационное, структурное, кадровое и иное состояние промышленного комплекса.

13. Организация и мотивация реализации стратегии преобразований. Указанный этап предусматривает создание комплексного механизма выполнения стратегии трансформации промышленного комплекса, обеспечивающего мобилизацию его потенциала, а также проектно-целевую интеграцию различного рода материальных и нематериальных ресурсов для системной работы по выполнению плана стратегических мероприятий и достижению необходимых результатов.

Важнейшей задачей на данном этапе является реальное вовлечение сотрудников предприятия в процесс осуществления преобразований и проактивное нивелирование сопротивлений, которые традиционно возникают при проведении масштабных изменений в социально-экономических системах.

14. Контроль и мониторинг реализации стратегии преобразований состоит в наблюдении за ходом стратегии с целью анализа корректности выполнения плана ее мероприятий, выявления возможных отклонений траектории развития промышленного комплекса от заданных параметров и общей оценки процесса трансформации его бизнес-модели. 
На этапе контроля и мониторинга менеджменту предприятия необходимо также оценить, приводит ли реализуемая стратегия институциональных преобразований к разрешению проблем и противоречий, выявленных на этапе проведения аудита рыночного состояния промышленного комплекса.

15. Корректировка стратегии институциональных преобразований предполагает организацию процесса постоянной актуализации стратегии, внесение в нее уточняющих или радикальных изменений в зависимости от динамики рыночной ситуации или стратегического видения руководства промышленного комплекса.

\section{Заключение}

В условиях трансформации хозяйственных отношений и становления цифровой экономики важное научно-практическое значение приобретает переосмысление и развитие существующей методологической основы стратегического управления индустриальными предприятиями. В рамках решения данной задачи автором разработана и обоснована методология формирования и реализации стратегии институциональных преобразований промышленных комплексов в цифровой среде, базирующая на инструментальной матрице и структурированная по уровням (философско-мировоззренческий, общенаучный, отраслевой-экономический и инструментально-технологический), элементам (категориальный аппарат, подходы, принципы, инструментарий) и содержательным блокам (теоретико-методологический базис, инструментальное ядро и тактические организационно-управленческие механизмы).

В результате исследования также предложен методологический подход, включающий 15 взаимосвязанных этапов и позволяющий решать полный цикл задач по проектированию и внедрению стратегии комплексных изменений производственного предприятия. Его отличительной особенностью и конкурентным преимуществом выступает возможность интегрировать вид стратегии и форму проведения институциональных преобразований, а также использовать сквозную систему планов по институциональной, функциональной, процессной, структурной, цифровой и инновационной трансформации бизнесмодели индустриального комплекса.

\section{Список источников / References}

1. Ансофф И. Стратегическое управление. Москва, Экономика, 1989. 519 с. [Ansoff, I. Strategicheskoe upravlenie [Strategic management]. Moscow, Ekonomika Publ., 1989. 519 p.]

2. Минцберг Г., Куинн Дж., Гошал С. Стратегический процесс. Концепции, проблемы, решения. Санкт-Петербург, Питер, 2001. 567 c. [Mintsberg G., Kuinn Dzh., Goshal S. Strategicheskii protsess. Kontseptsii, problemy, resheniya [Strategic process. Concepts, problems, solutions]. St. Petersburg, Piter Publ., 2001. 567 p.]

3. Kotter John P. Accelerate: Building Strategic Agility for a Faster-Moving World, 2014. $224 \mathrm{p}$.

4. Peter M. Senge, Art Kleiner, Charlotte Roberts, Rick Ross, Bryan Smith The Fifth Discipline Fieldbook: Strategies and Tools for Building a Learning Organization. Currency Moscow, 2010. 648 p.

5. Кэмпбел Д. Стратегический менеджмент. Москва, Проспект, 2017. 336 с. [Kempbel D. Strategicheskii menedzhment [Strategic management]. Moscow, Prospekt Publ., 2017. 336 p.] 
6. Щедровицкий Г.П. Избранные труды. Москва, Шк. Культ. Полит., 1995. 800 с. [Shchedrovitskii G. P. Izbrannye Trudy [Selected works]. Moscow, Shk. Kul't. Polit. Publ., 1995. 800 p.]

7. Загвязинский В.И. Методология и методика дидактического исследования. Москва, 1984. 10 c. [Zagvyazinskii V.I. Metodologiya i metodika didakticheskogo issledovaniya [Methodology and methodology of didactic research]. Moscow, 1984. 10 p.]

8. Ожегов С.И. Толковый словарь русского языка Москва, ИТИ Технологии, 2015. 944 c. [Ozhegov, S.I. Tolkovyi slovar' russkogo yazyka [Dictionary of the Russian language]/ S.I. Ozhegov, N.Yu. Shvedova. Moscow, ITI Tekhnologii Publ., 2015. 944 p.]

9. Прохоров А.М. Большой энциклопедический словарь. Москва, Санкт-Петербург, Норинт; 2002. 516 с. [Bol'shoi entsiklopedicheskii slovar' [Large encyclopedic dictionary]. Moscow, St. Petersburg, Norint Publ., 2002. 516 p.]

10. Пригожин А.И. Методы развития организаций. Москва, МЦФЭР, 2003. 864 с. [Prigozhin A. I. Metody razvitiya organizatsii [Methods of development of organizations]. Moscow, MTsFER Publ., 2003. 864 p.]

11. Курносов Ю.В., Конотопов П.Ю. Аналитика: методология, технология и организация информационно-аналитической работы. - Москва, Издательство «Русаки», 2004. 550 c. [Kurnosov Yu.V., Konotopov P.Yu. Analitika: metodologiya, tekhnologiya i organizatsiya informatsionno-analiticheskoi raboty [Analytics: methodology, technology and organization of information and analytical work]. Moscow, Rusaki Publ., 2004. 550 p.]

12. Гительман Л.Д. Преобразующий менеджмент: Лидерам реорганизации и консультантам по управлению. Москва, Дело, 2009. 496c. [Gitel'man L.D. Preobrazuyushchii menedzhment: Lideram reorganizatsii i konsul'tantam po upravleniyu [Transformative management]. Moscow, Delo Publ., 2009. 496 p.]

13. Зуб А.Т. Стратегический менеджмент. Москва, Аспект пресс, 2006. 416 с. [Zub A.T. Strategicheskii menedzhment [Strategic management]. Moscow, Aspekt Press Publ., 2006. 416 p.]

14. Галынчик Т.А.Управление изменениями. Нижневартовск, изд-во НВГУ, 2016. 120 с. [Galynchik, T.A.Upravlenie izmeneniyami [Change control]. Nizhnevartovsk, NVGU Publ., 2016. 120 p.]

\section{Сведения об авторе / About author}

Боев Алексей Геннадьевич, кандидат экономических наук, заместитель руководителя, Аналитический центр правительства Воронежской области. 394006 Россия, г. Воронеж, пл. Ленина, 12. E-mail:aboev@govvrn.ru

Alexey G. Boev, Candidate of Economic Sciences, Deputy head, Analytical center of the Voronezh region government. 12, Lenin square, Voronezh, Russia, 394006.E-mail: aboev@govvrn.ru 